\title{
ACTIVE EARTH DEFORMATION
}

\section{T.L. Grant-Taylor, G.T. Hancox, G.J. Lensen, L.E. Oborn, B.N. Thompson, R.P. Suggate*}

SYNOPSIS:

The introduction (part I) notes the N.Z. Geoliogical Survey's policy and practice on active earth deformation with its emphasis on standardisation and uniformity in the treatment of data and presentation of interpretations.

Part II defines the terminology relating to earth deformation, it classifies active faults and folds by strictly adhering to the available evidence of their past geological history of activity. Where evidence of past activity is missing, but the structure can be geologically identified and the absence of evidence can be shown to have been destroyed or obscured, criteria for classification as "Potentially Active" are presented.

The periodicity of movement and the risk of future movement are briefly discussed.

The need to separate data from interpretation is clearly indicated by the separate treatment in part III - presentation of data in geological maps and reports - and part IV Town Planning and Engineering Implications. The latter part requires the separate presentation of a Data Map and a Interpretative Map, and concise criteria are listed to achieve standardisation of interpretation.

The report ends with a brief and general discussion on the engineering implications of active earth deformation.

\section{INTRODUCTION}

In the study of active earth deformation, a major problem confronting geologists and engineers is to decide which structures should be classed as active. In making his assessment of the probability of future movement, the geologist is guided by the principle that the past provides a key to the future, so that a geological structure that has moved repeatedly in the recent geological past is likely to move with similar frequency in the future.

His assessment is, however, limited by the evidence seen in the field or obtained by subsurface investigations. Many different features which are evidence of earth deformation may be observed, but the geological record is far from complete. Deductions are limited, and may need revision in the light of later additional evidence.

The earth deforms by faulting or folding. In both cases tilting and subsidence and/or uplift are essential elements in the deformation.

The position of known active structures can be mapped and there is a need to devise a classification that will usefully indicate the amount and frequency of past earth movements and so be a guide to future movements.

Of active structures, faults provide the best information. At places along individual faults, the geologist can estimate the minimum value of the total displacement, and in some places the actual amount of total displacement since the formation of a particular reference surface. In addition, by observing the cumulative displacements of flights of river terraces he can conclude that many faults have moved repeatedly. He can also determine the minimum number and the possible magnitudes of individual movements that together are responsible for the total observed surface displacement.

Through studies of the development of the landscape, particularly of terraces, and the use of radiocarbon and other dating methods, the geologist can form an opinion of the relative ages of the individual surfaces cut by the fault. He can therefore estimate broadly the times at which some individual fault movements took place.

The object of this report is to state policy and practice of the N.Z. Geological Survey on active earth deformation by presenting:

- definitions of the terms relating to active earth deformation;

- a classification of active faults and folds;

- notes on the frequency of movement of active earth deformation and on the estimation of risk of future movement;

- some suggestions for the presentation of data on faulting;

- standards for extrapolation of known active earth deformation for Town and Country Planning purposes;

- a note on engineering implications of active faulting.

\section{ACTIVE STRUCTURES}

\section{I Definitions}

\subsubsection{Geological structures}

A Fault is here defined as a fracture at

* N.Z. Geological Survey. 
which relative displacement of the rocks on the two sides has taken place by tectonic movement parallel to the fracture; the surface of fracture is known as the Fault Plane. Breakage is rarely simple at major faults, and displacement is commonly distributed over a Fault Zone that can vary in width from a few metres to a kilometre or more.

A fault zone may contain rocks ranging from fault gouge ("pug") to crushed, sheared or shattered rock, but may include substantial volumes that have been relatively undamaged by faulting. In some areas (e.g. volcanic regions) and in some rocks (e.g. superficial gravel deposits), the fault zones are cormonly extremely narrow, as the faulted deposits are young and thus have experienced relatively few displacements.

A Fold is here defined as a geological structure which is the result of differential vertical movement without fracturing. Tilting that is not clearly part of folding is regarded as such in the context of active deformation.

\subsubsection{Fault Traces}

(a) A Fault Trace is a surface feature formed by displacement of the ground surface by faulting.

A Fault Trace is normally linear, marked by a scarp, sharp flexure, trench or fissure. Surface displacements associated with fault movement may be spread over the width of the fault zone.

(b) An Intermittent Fault Trace is one where the total length along which the trace is preserved is larger than that along which it has been subsequently destroyed or buried, provided linear continuity of the fault is known from geological evidence.

(c) A Bedding Fault Trace is a trace resulting from tectonic displacement on a bedding plane.

(d) A Compaction Fault Trace is a trace produced by differential compaction of unconsolidated deposits overlying an irregular basement.

(e) A Ridge Rent is a trace initially resulting from earthquake-induced failure within the upper part of steep sided ridges; the scarp commonly faces upslope and strikes subparallel to the ridge.

The state of preservation of a fault trace is a useful broad indicator of its age, provided that the stability of the surface materials, the climate, vegetation and cultivation are taken into account. Some fault traces are as old as 500,000 years, but the majority are less than 50,000 years old because over much of New Zealand erosion and deposition have substantially modified the ground surface within that time.

\subsection{Classes of Active Structures}

\subsubsection{Definitions}

In general terms an active fault can be defined as a fault that has moved in late geological time, and is expected to move again. A more precise definition is required, however, if a classification is to be developed. Thus an
Active Fault is here defined as one along which there is evidence either of surface movement in the last 50,000 years, or of repeated surface movement in the last 500,000 years.

In practice the evidence of movement normally consists of a fault trace cutting deposits or surfaces whose age may be either well or imperfectly known. Evidence that a fault is active may not extend along its full known length, but it should be recognised that future movement is not necessarily restricted to the section known to be active. Beyond that section the fault should be considered active for such a distance as is indicated by geological or geophysical evidence.

The general definition requires that an active fault should be expected to move again. Earth movements are related to deep-seated, long-term, causes. The faulting in some of the regions in New Zealand is dominantly horizontal; in others it is dominantly vertical. Commonly there is good evidence of successive movements along the same fault, and the next movement is expected to take place at the same fault plane.

In volcanic regions, faults that are due to volcanic collapse commonly occur as swarms in restricted belts, and future faulting is to be expected within these belts, but not necessarily along pre-existing faults. Such belts should be recognised in any scheme for fault classification and mapping, and an Active Fault Belt defined on geological grounds may extend beyond the known fault traces. Where isolated short traces have resulted from volcanic collapse, and no repetition is known or expected, the faults are not considered active.

Bedding faults may move again along the same bedding plane or develop along other bedding planes of similar dip and strike. The limits of an area of bedding faults are defined by geological evidence, and the area is described as an Active Bedding Fault Area.

An Active Fold is a structure along which there is evidence either of surface movement in the last 50,000 years or of repeated surface movement in the last 500,000 years.

While it is relatively simple to demonstrate the activity of a fault by the age of the surfaces it abruptly displaces, the activity of a fold is much more difficult to establish by the tilt of deformed surfaces. Folding of sediments of 50,000 to 500,000 years in age generally results in tilts ranging from those too small to measure to those of a few degrees. To conclusively demonstrate repeated movement, at least two reference surfaces need to be present and the difference in their tilts needs to be demonstrated.

Folds with half wavelengths of less than $2 \mathrm{~km}$ are not included as discrete structures provided that an associated active fault is recognized because they are predominantly associated with buckling close to faults. For broader folds, the mechanism of folding - whether by sudden movements or by gradual deformation is not known. But any initially horizontal surfaces with proven regional tectonic dips of over 10 minutes must have resulted from successive movements over long periods. 


\subsubsection{Classification of Active Faults}

In the fields of engineering and town planning, the main reason to classify active faults is to assess the relative reliability of future movement.

Because it is thought that a fault that has moved repeatedly in the past, is likely to move with similar average frequency, classification of active faults must be designed to reflect the history of past fault movements. In esserice, the more frequently a fault has moved in Late Quaternary time the more prone it is thought to be to future movement, and the higher must be its place in the classification.

In practice, three classes can usefully be used - with a high, medium and low frequncy of demonstrable past activity. In addition, some fault features can be classed as "Late Quaternary Fault Traces", but not as active faults; these have apparently moved only once in the last 500,000 years, but are not expected to move again.

The classification given below depends on the number of surface movements in three periods of late Quaternary geological time; of less than 5,000 years ago; from 5,000 to 50,000 years ago; and from 50,000 to 500,000 years ago. In judging the number of movements in these periods, geological as well as topographic inference, based for example on ages and degrees of deformation of rocks displaced, may be used, except that no fault without known surface movement shall be classed as active (see "potentially active" p. 7). The accompanying table shows the classification, which uses the combination of the movements of the fault in the last 5,000 years, and its movements in the two earlier periods.

\section{TABLE OF CLASSIFICATION}

note:

$$
\text { In applying the following classification }
$$

(1) Where there is no evidence preserved relating to any two of the time periods it is assumed that no movement occurred during those periods.

(2) Where the classification differs, according to the evidence in different pairs of time periods, the higher classification is adopted.

\begin{tabular}{|c|c|c|c|c|}
\hline \multirow{2}{*}{\multicolumn{2}{|c|}{ Movement during }} & \multicolumn{3}{|c|}{$5,000-50,000$ years } \\
\hline & & Repeated & Single & None \\
\hline & epeated & I & I & I \\
\hline $\begin{array}{c}0-5,000 \\
\text { years }\end{array}$ & Single & I & II & III \\
\hline & None & II & III & \\
\hline
\end{tabular}

Movement during $50,000-500,000$ years

\begin{tabular}{rcccc} 
& \multicolumn{2}{c}{ Repeated } & Single & None \\
\cline { 2 - 4 } $\begin{array}{c}\text { Repeated } \\
\text { years }\end{array}$ Single & I & I & I \\
\cline { 2 - 4 } None & II & III & III \\
\cline { 2 - 4 } & III & $*$ & \\
\cline { 3 - 4 }
\end{tabular}

\begin{tabular}{|c|c|c|c|c|}
\hline & \multicolumn{3}{|c|}{$50,000-500,000$ year } \\
\hline & & Repeated & Single & None \\
\hline \multirow{3}{*}{$\begin{array}{l}\text { P, } \\
5000- \\
50,000 \\
\text { years }\end{array}$} & Repeated & II & II & II \\
\hline & Single & II & III- & III \\
\hline & None & III & * & \\
\hline
\end{tabular}

* May be mapped as "Late Quaternary Fault Trace".

This classification can also be applied to active fault belts and active bedding fault areas.

\section{Examples}

The following examples illustrate the application of the classification. They record the geologist's conclusions regarding the timing of individual or repeated movements -

Fault Movements

Estimated ace of movement

Example 1. (years)

$\begin{array}{ll}\text { Single movement } & \mathrm{AD} 1884 \\ \text { Two movements } & 15,000-50,000\end{array}$

The type of evidence might be: (i) historic movement; (ii) progressively greater displacement of two surfaces judged to be 15-50,000 years old. The fault is Class I.

Example 2.

$\begin{array}{ll}\text { Single movement } & 15-20,000 \\ \text { Two movements } & 80-250,000\end{array}$

The type of evidence might be: (i) faulted surface dated in the $15-20,000$ year range; without the presence of any 0-5,000 year surface capable of recording displacement, the older $(5-50,000$ year age range is chosen; (ii) progressively greater displacement on two older surfaces judged to be 80-250,000 years old. The fault is class II.

\section{Incomplete Evidence}

Geological evidence is cormonly incomplete. Evidence that a fault has moved once in the last 5,000 years may be readily available, but it may be rpossible to demonstrate that more than one movement has occurred. It should be noted that the only faults to be placed in Class I are those that can be so classified with certainty. Lack 
of evidence will exclude faults from Class I, rather than place them in that category, except where the classification varies along the regional strike of a trace in which case the highest classification given is applicable to the entire fault.

Compaction Faults and Ridge Rents will not be classified unless repeated movement can be demonstrated.

\section{Late Quaternary Fault Traces}

"Late Quaternary Fault Traces" shown on geological maps include traces of faults in all the above classes and also:

(i) faults with only one record of surface movement in the period 50,000 to 500,000 years ago;

and

(ii) faults that have moved once only, regardless of when, in the late Quaternary, and that, for valid geological reasons (e.g. because they are due to superficial volcanic collapse), are not expected to move again.

\subsubsection{Classification of Active Folds}

The classification of active faults can be applied, with the additional criterion that surfaces with proven regional tectonic tilts of over 10 mintues can be regarded as having undergone repeated deformation.

\subsection{Potentially Active Structures}

Where there are reasons to suspect that evidence of activity has been destroyed or obscured, the following definitions may be applied:

A Potentially Active Fault is a geologically identified fault whose strike, length and physiographic expression are similar to those of the principal active faults in the same tectonic regime, but whose activity over the past 500,000 years cannot be demonstrated.

A Potentially Active Fold is a geologically identified fold whose strike, length and dips of sediments of the same age are similar to those of the principal active folds in the same tectonic regime but whose activity over the past 500,000 years cannot be demonstrated.

A Potentially Active Bedding Fault Area is a geologically identified area whose tectonic setting is similar to active bedding fault areas in the same tectonic regime but whose activity over the past 500,000 years cannot be demonstrated.

Provided the reasons for lack of evidence of activity are discussed, potentially active faults, folds and areas may be classified as I, II or III after comparison with the active structures in that region.

A structure classified in one of the active classes may also be classed in a higher potentially active class.

\subsection{Periodicity of Movement at Active Faults}

It is thought that in any particular area sudden earth shifts and their associated earthquakes (strain release) occur spasmodically over a period of several hundred years followed by longer periods of relative quiescence during which strain is accumulating.

Known historic displacements at faults in New Zealand demonstrate single fault displacements ranging up to 7 metres horizontally or vertically and extending over distances up to $150 \mathrm{kms}$. Geological evidence indicates that comparable movements have taken place in the past.

Judged by the ages and total displacement of surfaces, the periodicity of sudden displacement at any particular locality on some active faults in regions of dominantly horizontal movement appears to be about once in 1000 years. In north-west Nelson where the regime is dominantly compressional and where fault movement is dominantly vertical, this periodicity of fault movement is greater and may reach 10,000 years. In the volcanic belt which is dominantly under tension the periodicity is thought to be less than 1,000 years.

Whatever the periodicities of the principal earthshifts, a major earthshift on one fault may result in sympathetic small movement on other adjacent active faults.

As stated in the introduction, movement at existing faults will continue, or new faults will be produced, in the near future at a rate similar to that of the geologically recent past, but a single movement, however recent, does not necessaruly imply movement at that fault in the near future.

Even within classes, the risks may vary and each fault, or section of a fault, must be discussed on the basis of the particular data available.

\section{PRESENTATION OF DATA IN GEOLOGICAL MAPS AND REPORTS}

The object is to give information on past earth deformation and to make some assessment of the probability (risk) of future deformation.

\subsection{Basic Data}

Information on past earth deformation comes from a knowledge of -

(1) the ages of the sediments or rocks displaced;

(2) the ages of displaced erosional or depositional surfaces;

(3) the amounts of displacement of the rocks, soils, and surfaces

(4) historic displacements.

In special purpose geological maps active earth deformation is presented and is shown in appropriate classes. Active faults, fault belts and folds are shown by continuous lines and fold symbols except for presumed extensions and potentially active structures.

Active fault traces should be shown within any fault belt, the margins of which should be set to take into account the possibility that future movement in the belt may be outside the 
limits of the known traces.

The table classifying active faults should be reproduced on the margins of these maps on which such faults are shown; the text should summarize the reasons for mapping any fault in Class I.

On general geological maps, Late Quaternary Fault Traces are shown in brown. The black long-dashed fault symbol across Late Quaternary deposits can be used to indicate that, although fault traces are not known along stretches where it is used, those young deposits are inferred to be faulted. Along the most active faults the black short-dashed fault symbol would normally be used only where the youngest river alluvium or lake waters conceal the fault.

\subsection{Reports}

Unless already published or otherwise available, the data relating to fault displacements should include the following:

(i) Description of fault traces (cf. "Late Quaternary Tectonic Map Series").

(ii) Discussion of the possible continuation of the active fault between individual traces.

(iii) Discussion of the possible extension of the active fault beyond the last trace.

(iv) Discussion of fold axes and surface tilts.

(v) Any other relevant points.

The above data will be sumarised in terms of when movements are estimated to have taken place, as in the examples.

\section{TOWN PLANNING AND ENGINEERING IMPLICATIONS}

Although a number of recommendations are set out below, it must be emphasised that they are for general guidance and that every major construction project must be treated individually. Large or vital structures should certainly be the subject of geological reports for each individual site. This is particularly important where it is suspected that fault traces have been obliterated by human or natural agencies and also near the junction of two active faults.

\subsection{Mapping of Active Faults and Folds for Town Planning Purposes}

While buildings and constructions anywhere in New Zealand can be expected to become subjected to the unavoidable effects of earthquake shaking, the destructive effects from permanent earth displacement across and close to active geological structures are additional and can be avoided where these are known and carefully located.

In district scheme planning, the presence of active structures and their extensions need to be taken into account and where practical mapping is to be at a scale of $1: 12,500$ or larger. This forms the data map, without which no interpretative map shall be provided.

All active structures need to be mapped and classified.

\section{Data Map shows}

(a) the surface evidence of active structures (scarps, matched displaced surfaces, offsets, tranches, ridges, sag ponds, flexures, tilts on surfaces and/or young sediments etc.), precisely located and each individually described in an accompanying table;

(b) subsurface evidence exposed, similar to (a) ;

(c) similar evidence exposed by human activity, or available from existing records.

II Interpretative Map

This consists of a copy of the base map (which contains all data) with the interpretation entered in red as follows:

III Tectonic Reference

(a) positive surface features (in I (a) above) can be extended as full lines for distances of $100 \mathrm{~m}$ in either direction (i.e. features up to $200 \mathrm{~m}$ apart would be joined along the presumed strike) provided

(i) the trace over the last $100 \mathrm{~m}$ does not change significantly in strike;

(ii) the trace does not show evidence of dying out, by either decreasing throw (either horizontally or vertically) on one single surface, or by the presence of a termination bulge or sag;

(iii) reasonable evidence of the fault strike is available e.g. gouge or shearing along the line of strike, subsurface drillhole data, geomorphological lineations, precise geophysical evidence etc.;

(iv) with good reason it is possible to explain the absence of surface features where the extension is made (e.g. subsequent erosion or aggradation, urbanisation etc.).

(b) The full lines may be extended as dashed lines for up to $10 \%$ of the length or intermittent length of the trace with a maximum of $500 \mathrm{~m}$ where geological or geophysical evidence (see (a) (iii)) defines the fault within $\pm 25 \mathrm{~m}$.

(c) As for (b), but geological or geophysical evidence defines the fault within $+50 \mathrm{~m}$. This extension will be shown as dash-dot.

(d) Potentially active structures will be shown as dot-dot.

The tectonic reference will be thus: 


$$
\begin{aligned}
& \text { - _ - extension defined to } \pm 25 \mathrm{~m} \text { accuracy } \\
& \text { _. _ _ " " to } \pm 50 \mathrm{~m} \text { accuracy. }
\end{aligned}
$$

(e) Where a fault cannot be located but is certain to continue beyond any extension indicated above, the following wording will be put on the map in the appropriate place: "Concealed fault, location unknown". The text will discuss the area within which the fault exists and will indicate the need for investigation of its location in relation to any proposed major or vital construction.

\section{Accompanying Report}

The interpretative map is accompanied by a covering report which:

(a) Invites the local authority to survey the fault traces into their cadastral schemes from pegs located by the N.Z. Geological Survery;

(b) draws the attention to the significance of the tectonic reference for the accompanying map;

(c) gives the assessed classification, and the reasons for each mapped Active and Potentially Active structure;

(d) states "The ground surface may suffer appreciable distortion over a width of $20 \mathrm{~m}$ on either side of the fault and any structure sited across the fault may be destroyed". It may be necessary to add "The resulting $40 \mathrm{~m}$ zone has in some cases been placed on one side of the fault only. Where the surface evidence is complex and occurs in a zone, the $40 \mathrm{~m}$ zone has been increased by the width of the zone of surface deformation";

(e) dates of historic fault movement will be given in the text.

\subsection{Engineering Implications}

\subsubsection{Shaking damage to constructions adjacent to an Active Fault}

Providing an adequate earthquake-resistant design of building and foundation is adopted, the danger from vibration does not appear to be any greater close to a fault than at any other place in the neighbouring area with the same foundation conditions. No special recommendations are therefore made.

\subsubsection{Constructions within Fault Zones}

A great potential hazard in a fault zone (outside the designated width associated with the fault trace) are the porr foundation characteristics of the crushed, sheared and shattered rock. This is an engineering problem.

The weakness of this rock implies, however, that future movement may not be restricted to the trace along which the most recent past movements have occurred. Examples are known of migration of active fault traces within a fault zone, but this is thought to be a long-term phenomenon. For the purposes of present-day building construction it is probably that renewed fault activity will follow closely the existing trace. Nevertheless town planners dealing with entirely new urban development schemes might be able to utilize fault zone areas in ways that take this into account (e.g. by zoning them as recreational areas, minor road reserves, etc.).

\subsubsection{Additional Evidence}

Important additional evidence may be uncovered during the site testing or foundation excavation. In some instances specific investigations (drilling, trenching, etc.) may be needed to accurately locate the fault zone before the designs and location of a proposed structure are finalized.

\subsubsection{Strength and bearing characteristics of Fault Zone material}

In cases where the activity or potential activity of a fault zone is not known, or where the fault zone is known not to be active, the characteristics of the foundation materials are of prime importance. The strength and bearing characteristics of fault zone materials are extremely variable; in some cases these may be weak and incompetent, while in others they may be stronger and acceptable as a foundation. The extent, contrast, sheared and weathered nature and strength characteristics of any such materials within a proposed foundation therefore needs to be ascertained at an early stage during the site investigation and taken into account during the planning and design stages.

\subsubsection{Effects of tilting and horizontal movement}

Tilting resulting from faulting or folding can result in subsidence and uplift. This can result in inundation of coastal and lake access, while tilting in the flanks of folds or involving entire fault blocks may also affect sensitive installations, including irrigation and drainage systems.

Horizontal displacement which reaches its maximum close to transcurrent faults dissipates outwards at a decreasing rate. Services requiring pipes or cables should cross faults, where this cannot be avoided, in such a way that they will shorten rather than lengthen.

\section{Acknowledgements}

Published with the permission of the Director of the New Zealand Geological Survey.

This paper is a direct transcription of NZGS Report 89 (1979). 